\title{
Building Sustainable Industrial Areas: Experience and Perspectives from the Mediterranean and Western Balkan Countries
}

\author{
R. Preka*1, M. Tarantini ${ }^{1}$, A. Dominici Loprieno ${ }^{1}$, M. Litido ${ }^{1}$, \\ M. Segreto ${ }^{1}$
}

\begin{abstract}
:
An EU research project (Mediterranean Eco-Industrial Development, (MEID)) which involves different actors from Mediterranean and Western Balkans region, is currently in progress. Its general objective is to provide innovative management figures and a decision support tool (model) to plan, build and manage more competitive Sustainable Industrial Areas (SIA) in the involved region.

In order to correspond to a coherent solution, an accurate research has been performed. The methodology implemented to detect the main issues under survey has been a SWOT analysis of several target IAs.

Following its results, there have been defined the most relevant aspects aiming at sustainability of IAs in the area. The model introduces or encourages the continuous improvement of environmental performances of the Mediterranean industrial areas in the following fields: integrating production and dismissal of solid wastes, energy saving and use of renewable energies, reducing water consumption, better viability and avoid the deposit of dangerous material. Thanks to this "green approach", SMEs will be the final beneficiaries, fostered to eco-innovation, competitiveness and transnational cooperation. This paper presents the general context and results of the MEID project.
\end{abstract}

\section{Introduction}

Industrial and Technology Parks play a key role in regional and urban economies, as they can be a source of economic and technological development necessary for the community. Unfortunately, they can also be dreary, unfriendly places where are generated problems such as pollution, traffic congestion and land degradation. These issues have negative effects on people working in these productive areas and citizens living nearby.

Recent Green Industry approaches - developed in the framework of the Green Economy - contribute to decoupling growth from resource use and pollution by

$\mid{ }^{1}$ Italian National Agency for New Technologies, Energy and Sustainable Economic

Development - ENEA

*Corresponding author 
introducing new management and production practices in enterprises and stimulating the creation of environmental technology and service providers, i.e. businesses ranging from small-scale re-cycling operations to the renewable energy technology companies.

The proponents of Eco Industrial developments retain that it is one way to implement sustainable development. Dunn and Steinmann [4] debate the different ways in which the objective of sustainable development could be reached. In economic terms waste minimization has benefits for all parties: reducing waste disposal costs on one hand, and expenditure in raw materials on the other. In environmental terms the profits are achieved in the same time by both, waste reduction and resource use. The social gains in this case are more light but life style gains may be achieved by cleaner industrial practices. Kurup et al. [7] has emphasized that the economic, social and environmental implications are needed to be considered for each stage of the synergy project life cycle (i.e. planning, design, construction, operation, maintenance and decommissioning).

All this premised, it is easily comprehensible the big attention paid, in latest years, to the Sustainable Industrial Areas (or Eco-Parks), differently conceived (and often differently named) over the whole world, as a successful example of contribution not only to decrease pollution and manage all the environmental aspects, but also to increase areas potential economic value and build up better local communities relationships.

\section{Objectives of the study}

This paper wants to briefly discuss the main elements of a joint Mediterranean Sustainable Industrial Area by investigating the difficulties and potentials of the establishment of these areas in the Mediterranean regions. Moreover, it also wants to give an outline of the MEID model for Sustainable Industrial Areas which has been developed in the framework of the MEID project financed by the MED program of the EU. The project involves partners from six Mediterranean and the Western Balkans countries (Italy, Greece, France, Spain, Malta and Bosnia Hercegovina) and has also created a database with the best practices of the Industrial Areas of the involved partner countries.

\section{Key elements of the MEID model}

The approach of the Eco-parks is generally focused on the environmental aspects of the area and company management. Nevertheless the approach to sustainability needs a systemic action that involves the other two dimensions 
which are the social and the economic one. Indeed, the MEID modelintends to integrate in a unique procedure all these dimensions. The economic goal can be reached by sharing plants and services counting on the economies of scale, as well as by image improvement at a company and territorial dimension with consequent enhancement of competitiveness and attractiveness of the whole area. The development of other business activities connected to the trend of green economy are other potentials that the approach to sustainability can facilitate. As far as the environmental dimension is concerned, the model introduces or encourages the continuous improvement of environmental performances of the Mediterranean industrial areas in the following fields: integrating production and dismissal of solid wastes, energy saving and use of renewable energies, reducing water consumption, better viability and avoid the deposit of dangerous material. The model aims to reduce environmental impact but also to harmonize regulations across similar territories, optimize social welfare gains and sustain competitiveness. The social aspect in this case is mostly intended as a service for the area, its employees and the territory.

The overall key elements that a sustainable industrial area, as figured out by the MEID model, should have, are the following:

> Unitary Management. The management of the area as a whole, not only at a firm level, allows the achievement of sustainability objectives as described above. In this case, a single organization such as a Managing Consortium (MC) would be useful for the management of many joint aspects of the area. Ideally, it represents the settled firms, acts as an interface with the local authorities and other institutional relations, as well as manages the area and is responsible of its environmental performances.

$>$ Shared industrial policy of the area. Close cooperation among settled industries and Local Authorities involving Industrial Associations, energy, water and waste management companies, is needed. Its function is to reach a shared vision and gain a wide consensus over the Area Industrial Policy;

$>$ Involvement of stakeholders. Another aspect to take under consideration is the involvement of stakeholders in the management decisions of the area. In this casefollowing the path of Agenda 21, a consultative Local Forum which represents the Area stakeholders can be a way of involvement. Examples of stakeholders: citizen associations, non- governmental organizations, trade unions, representatives of the companies, Local Authorities, trades associations, etc,. 
D High quality infrastructures. The SIA must be endowed with shared plants and/or services for the management of the critical environmental, social and economic aspects. (e.g. centralized WWTP, architectural planning of the area, sustainable buildings, mobility of persons and goods)

The main aspect of a Sustainable Industrial Area in terms of competitiveness is the added value of collaboration among enterprises in managing environmental and organizational issues. The competitiveness coming from this approach can be summarized in the following directions:

* Competitive advantages due to optimization and economies of scale of $\mathrm{R} \& \mathrm{D}$ and purchasing costs, advantageous financial support, knowledge sharing, higher innovation rates, favorable industrial atmosphere which ensure lower transaction costs, better human capital, widespread entrepreneurship, new services;

* The challenge of Eco-innovation and the need to manage the life cycle of the product is a strategic advantages in exploiting company synergies;

* Regulatory compliance and relief due to the increasing request by the law to respect environmental norms;

* Competitiveness of the territory.

\section{Materials and methods}

To understand the successful elements that can contribute to develop sustainable industrial settlements and, in the same time, the barriers or obstacles that have to be overcome, key strategic information has been collected in MEID associated countries and analyzed by a SWOT (Strengths - Weaknesses Opportunities - Threats) analysis.

SWOT analysis is a strategic planning method used to evaluate the Strengths, Weaknesses, Opportunities and Threats involved in a project or in a business case. As far as the IAs management is regarded, by carrying out the SWOT analysis it is possible to have a full comprehension of the situation, solve crucial points or to develop new strategies towards sustainability. In Figure 1 the general idea and concept of the SWOT analysis is illustrated.This analysis points out the internal conditions (strengths and weaknesses) of an Industrial Area, thus, the aspects that can be influenced directly from internal organizations; and the external factors (opportunities and threats) that are not influenced by the Industrial Area, but still are very important for its performance. 


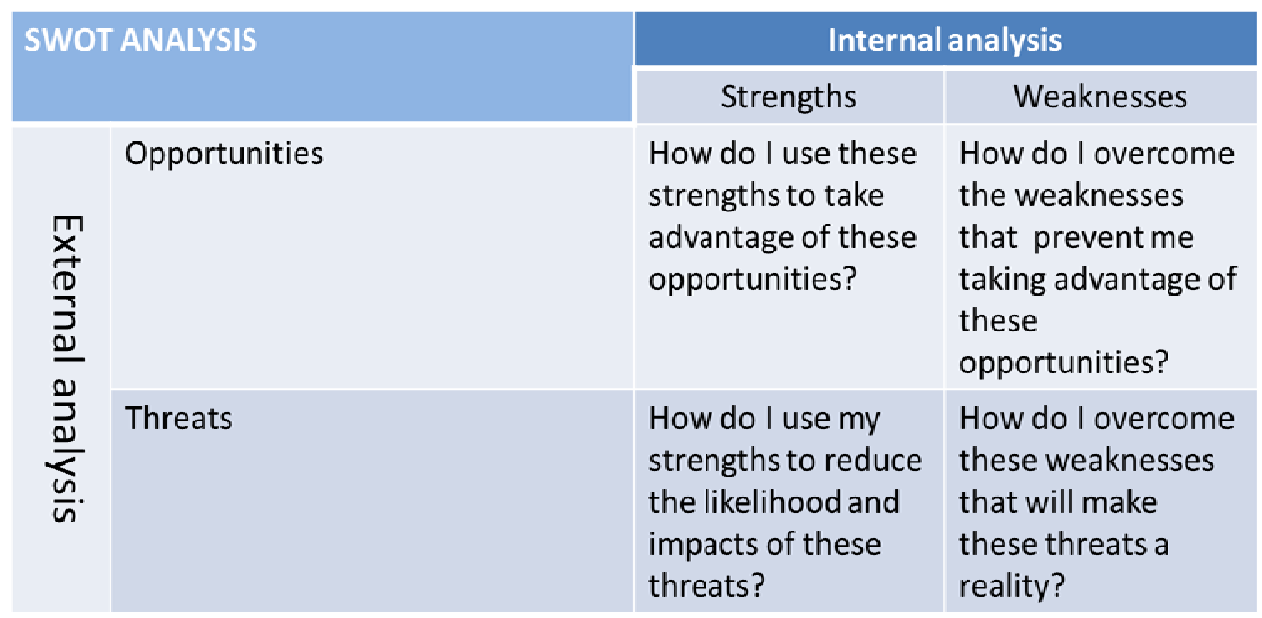

Figure 1 - General idea and concept of the SWOT analysis

The analysis has been performed considering the three aspects: i) environmental, ii) economic and iii) social. An appropriate questionnaire divided in four sections has been prepared and administered to the partners. The sections are listed below:

1. Legislative framework

2. Rules for IA planning

3. Environmental Management of the Industrial Areas

4. Infrastructures and centralized services

The analysis and the information gathered from the questionnaire has been useful:

To detect risks and difficulties in the implementation of a SIA model;

To identify the "state-of-the-art" of the SIA concept;

To determine the best experiences or Best Practice for SIAs

The questionnaire was then released to related stakeholders. All the partner countries, Italy, France, Spain, Greece, Malta and Bosnia-Hercegovina, have participated in the surveys giving to the research a regional dimension. Each partner has released the questionnaire to national and local relevant stakeholders giving out a national profile of the issue. The partner in charge of the collection of national analysis has gathered all the contributions synthesizing the results and pointing out the main common points.

The analysis presented in the following sections is based on areas which can be considered as the "best examples" for their approach to sustainability in all the studied countries. The point is to study at which extent this concept, which is 
pretty new and still not very well defined, is taken in by the area managers, local authorities and the society. It is not a study of the average situation, but rather a study of the average of "the excellence", with the idea to evaluate and systematize the best practices and build up a truly Mediterranean sustainable area model. The average situation of the industrial areas in the studied countries is very different. Generally they do not have the facilities which will be described for the examined areas (dedicated wastewater treatment plant, industrial waste management facilities, photovoltaic or cogeneration plants), the unitary management is lacking and very few centralized infrastructures and common services are present. The following conclusions are therefore related strictly to the best examples, for which should be stressed that they do not represent the average situation in the region. The sections "Legislation" and "Rules for Industrial areas planning" are instead representative of the regions in which the industrial areas are located.

\section{Analysis of the results}

The analysis confirmed, as first finding, the convergence of the Industrial Area conditions and profiles in the examined Mediterranean countries. In fact, despite the large variability of industrial settlements in Mediterranean countries, some common elements, such as the large prevalence of SMEs, the similarities of environmental problems faced by enterprises and the common legislative background (European Directives) can be identified. This finding gives the possibility to draw common guidelines for a sustainable management of the Industrial Areas. Hereafter the main results of the SWOT analysis are presented.

\subsection{Legislation}

Legislation concerning IAs, despite the common background of the European Directives, is quite different in the studied countries and the approach to sustainability is even more heterogeneous. It should be mentioned that despite a law defines an IA in all the countries, a specific law concerning Sustainable Industrial Areas is only present in Italy.

Here, the concept has been introduced by the Bassanini law which delegates to the regions the detailed regulation on the ecologically equipped areas but still, it gives some basic reference elements such as quality infrastructures and systems and unitary management of the infrastructures and services.

Another interesting approach which has some valuable experience in the side of the environmental care is the "EMAS cluster" registration. It is ruled by a technical document of the Italian Ecolabel-Ecoaudit Committee which has the 
objective to promote the environmental improvement not only at a firm level but also at territorial level.

In France there can be mentioned the national initiative named 'Grenelle de l' environment' which was organized in order to take long-term decisions regarding environmental issues and sustainable development, to restore biodiversity and other related issues.

Other initiatives are mostly local such as the Spanish municipality of Vilamarchant which gives economic incentives to those enterprises that set up in the SIA, respecting certain environmental measures. Other countries such as Greece, Malta and Bosnia-Hercegovina don't have anything pushing the IAs to become sustainable.

Moreover Greece and Italy have public-private organizations (in Italy named ConsorziedEnti di industrializzazione), created in the decade after World War II to support industrialization of depressed areas, which still manage important industrial areas in a unitary way and that can still be a very important element to boost the sustainable management of IAs.

\subsection{Rules for Industrial areas planning}

Industrial areas in the Mediterranean region are located and planned by urban means which are developed on local or regional level depending on the extension of the area, the country and other singular characteristics. Urban tools define criteria in order to define the procedure of selection of the site, according to infrastructures location, proximity to residential areas, previous existence of industrial premises or the environmental impact generated.

Still, this aspect is not highly regulated in none of the investigated areas, releasing many lacks in different directions that could be recalled to a sustainable path. Thus, generally future clients or prospects are not considered in terms of building norms, disposal or services, no forums with stakeholders are considered in the phase of IA's location etc.

\subsection{Environmental Management of the Industrial Areas}

All the areas which adopted some good practice such as centralized infrastructures and innovative services, have a Managing Company (MC) which, depending on the area and country, has different functions and dimensions. Generally, the managing company is either public or private, and in most of the cases, it is also a mixed private and public one. The MC offers very diverse environmental and social services to the areas and the settled companies. Moreover, in all cases the $\mathrm{MC}$ does not have a coercive function or sanctioning power so it is impossible for these organizations to impose norms or other to the enterprises. 


\subsection{Infrastructures and centralized services}

The most widespread infrastructures and centralized services assessed in the studied areas are reported in a BAT database. While the environmental practices are quite widespread, it is evident that social ones are still weak, and that few common actions are foreseen on the economic aspects.

\section{Application of the MEID Model}

The MEID model is to be intended as a series of necessarysteps to be followed to implement a sustainable managementof Mediterranean IAs. Since the investigated areas havedifferent levels of management and a large variability ofcharacteristics, three different paths to reach a sustainablemanagement have been detected, to be followed on the basisof the starting point of the IA. An incremental approach hasbeen adopted to ensure the model applicability to new, aswell as already operating non structured and structured IAs.

\subsection{New Industrial Areas}

The first path of the MEID model describes the steps that have to be pursued during the planning and the design phase of a new industrial area.

In the planning phase of a new industrial area, different choices and scenarios have to be considered which have also to deal with the related environmental impacts. On this purpose, the MEID procedure identifies Strategic Environmental Assessment (SEA) [step 1] as the main tool for the environmental assessment.

There are two reference tools for the design of new industrial areas: the Basque Guidelines for the sustainable development of urban projects realized by the Sprilur Group of the Basque Region and 


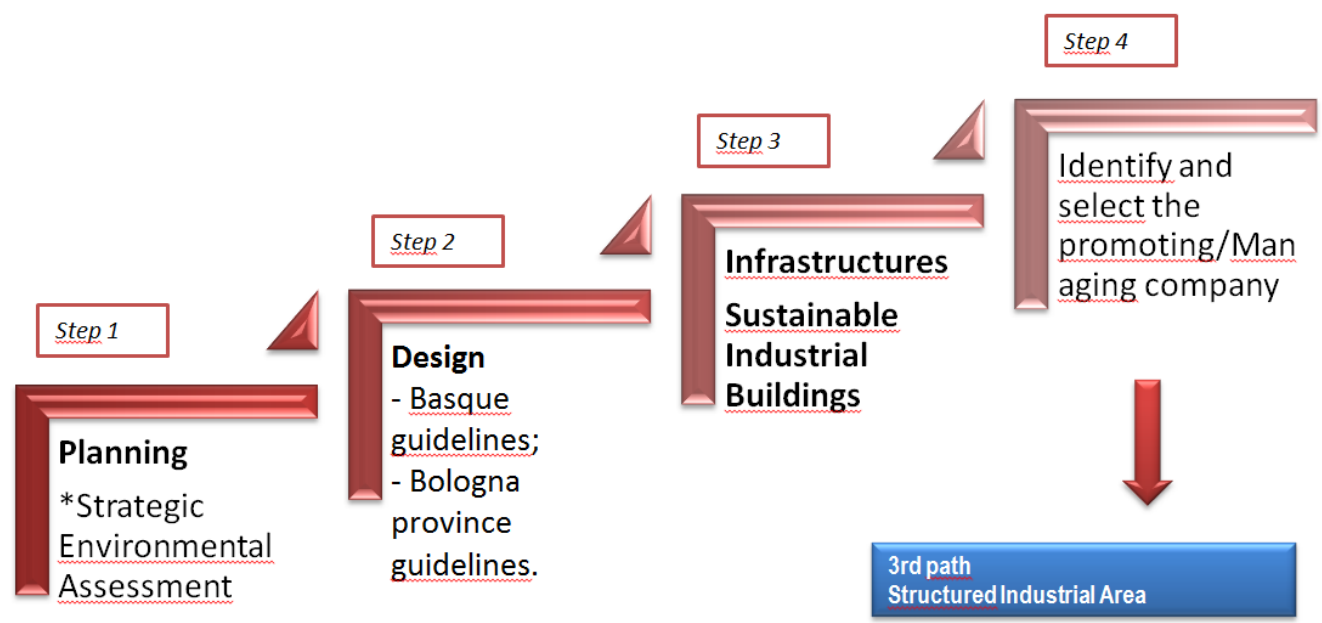

Figure - Planning and Design steps for new Industrial Areasthe Bologna Province Guidelines for the realization of Ecologically Equipped Productive Areas [step 2].

For the Industrial Buildings design, the reference document is the Guide for eco-efficient industrial buildings defined within the MEID project [step 3]. The path finishes with the individuation of the Promoting Company of the industrial area [step 4] which has to be involved in the previous steps and consequently, start the implementation phase of the MEID essential requisites (path 3)

\subsection{Non structured Industrial Areas}

The second path of the MEID procedure describes the steps that an industrial area, which is not managed at all but wants to be pro-active, needs to carry out to apply the MEID model approach. Despite the approach is mainly based on private initiative, the promotion of these actions by the Local Authorities is the best way to start-up the process in all Mediterranean countries.

Knowing the industrial area [step one] and its actors is the first step to implement any managing process. At an operational level it is necessary to create a map that helps to quickly locate and identify the settled companies and the free areas including the internal road network. Knowing the activities of the settled companies [step two] means promoting the growth and the sustainability of the area. Local Authorities, Development Agencies and the companies can use the gathered information for a proactive economic development. The collaboration among companies is a fundamental step to move forward sustainable development of industrial areas. It is very important to identify common objectives [step three] (environmental, social and economic) and choose priority objectives according to the needs of the companies. 


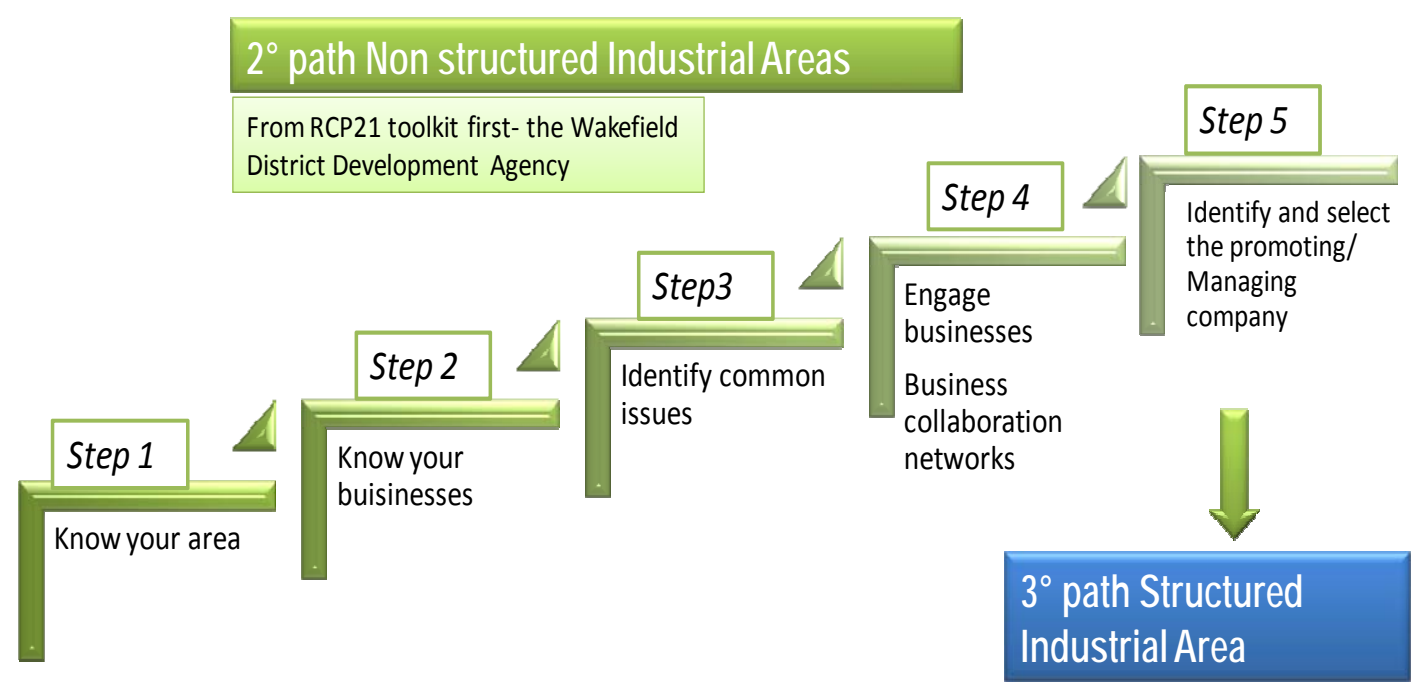

Figure - Step of non structured industrial area

A Business Collaboration Network (BCN) [step four] is a business - led group of businesses and other agencies that have a shared interest in working collectively to address particular issues, problems or joint needs of the businesses located on the park.The path is closed when the Promoting Company of the area is identified [step five]. The Promoting Company can propose itself as Managing Company or can finish its role as soon as the Managing Company is organized and operative.

\subsection{Structured Industrial Areas}

Path 3 follows at a conceptual level the previous paths: in the case of a new industrial area it follows the phase of the planning and design, and in the case of an existing non structured area, the phase of knowing the area and the collaboration of the enterprises which is compulsory for the full application of the MEID model. In this path it is more appropriate to talk about elements of the model and not steps as they can be applied without a chronological progression.

The Managing Company must have a recognized legal form. It has to represent the enterprises and it should also be recognized by the public system.An advisory forum which should be composed by representatives of the companies, Local Authorities, category associations and general stakeholders, should be organized and coordinated by the Managing Company. 


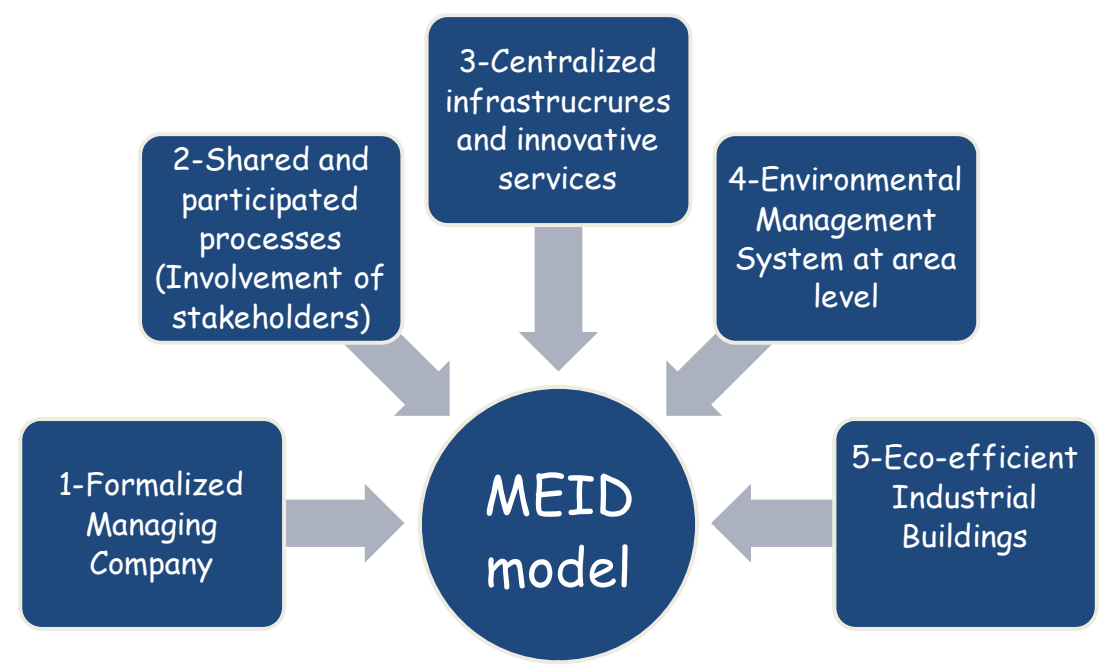

Figure - Elements of structured industrial areas

The forum allows to gather the stakeholders point of view on the most critical aspects of the management of an industrial area such as the identification of the weak points and the improvement actions.Following the phase of the analysis of the needs, the industrial area should be equipped with centralized state-of-art plants, able to exploit economies of scale and innovative services for the management of environmental, economic and social aspects. The industrial area by its the Managing Company should implement at least a non-formalized environmental management system. Finally, a MEID Guide for the Construction of Environmentally Sustainable Industrial Buildings is the reference document for the MEID model.

\section{Conclusions and recommendations}

The MEID project, in line with recent European policies on environmental performances and economic development, has allowed the definition and testing of an organizational and management model for the industrial/productive areas that aim to improve their own environmental, social and economic performances. Nevertheless, the SWOT Analysis of the areas has pointed out the fragile introduction of the concept of sustainability in the Industrial Areas of the partnership countries. It should be noticed that the examined areas are the most evolved ones in this perspective, but they still lack important interventions and systematic integration of this concept into their working activities. Even though 
some best practices are listed, they are present only in some of the areas and not fully functional.

On the other side, it is important to keep in mind that the process of the conversion of the IAs into Sustainable ones is still in the beginning, and to date no area has completed the transformation. Thus, it is still early to talk about Sustainable Industrial Areas even though a great effort is being made. Nonetheless, this analysis shows that the approach to sustainability has started and many actions and problems that sustainability addresses have been faced and taken in consideration.

The areas located in the regions that have already legislated in the direction of sustainability have a great opportunity to take advantage on it and accelerate their conversion. Still, it remains a slow process in these regions as well, also due to the lack of economic incentives and significant regulation relief. A careful consideration in this direction should be done by the Local Authorities. These are the first ones that can boost the conversion of the areas into sustainable ones. Finally, action is needed in three directions: the cultural one; new green strategies within enterprises and more cooperation among them, more involved local and authorities and public administration in order to make this passage possible.

\section{References}

Cote, R. P., (2000) A primer on industrial ecosystems: a strategy for sustainable industrial development. Halifax, Industrial Ecology Research and Development Group, Dalhousie University.

Andrews C.,(2001) Building a micro foundation for industrial ecology. Journal of Industrial Ecology 4 (3): 35-51

Frosch RA, Gallopoulos NE.,(1989) Strategies for manufacturing. Scientific American. 261 (3): 94-102

Dunn BC, Steinmann A.,(1998). Industrial ecology for sustainable communities. Journal of Environmental Planning and management 41(6). 661-672.

Cote R.P, Cohen Rosenthal E.,(1998). Designing eco-industrial parks: a synthesis of some experiences. Journal of cleaner production 6: 181-188.

Lehtoranta et.al.,(2011) Industrial Symbiosis and the policy instruments of sustainable consumption and production. Journal of cleaner production $1865-1875$

Kurup, B., Altman, W. and Van Berkel, R. (2005). Triple bottom line accounting applied for industrial symbiosis. Australian Life Cycle Assessment Society Conference. Sydney, Australia. 